\title{
Sensorless Predictive Direct Power Control PDPC-SVM For PWM Converter Under Different Input Voltage Conditions
}

\author{
Ismail Boukhechem ${ }^{1}$, Ahcen Boukadoum ${ }^{2}$, Lahcene Boukelkoul ${ }^{3}$, Houssam Eddine Medouce ${ }^{\mathbf{4}}$ \\ 1,2,3 Department of Electrical, Electrotechnical Laboratory, University of August 20 Skikda, Algeria \\ ${ }^{4}$ Department of Electrical, Universitas frères mentouri, Algeria
}

\begin{tabular}{l}
\hline \hline Article Info \\
\hline Article history: \\
Received Aug 25, 2019 \\
Revised Dec 2, 2019 \\
Accepted Mar 26, 2020 \\
\hline
\end{tabular}

\section{Keywords:}

Predictive Direct Power Control (PDPC)

Virtual Flux (VF)

Space Vector Modulation

(SVM)

\begin{abstract}
In this paper, a new virtual flux (VF) based predictive direct power control (VF-PDPC) applied for a three-phase pulse width modulation (PWM) rectifier is proposed. The virtual flux estimation is performed using a pure integrator in series with a new adaptive algorithm in order to cancel dc offset and harmonic distortions in the estimated VF. The introduced structure is able to produce two virtual flux positive sequence components orthogonal output signals under unbalanced and distorted voltage conditions. The main features of the proposed virtual flux estimator are, it's a simple structure, accuracy, and fast VF estimation over the excited integrators. Therefore, the estimated VF is then used for robust sensorless VF-PDPC with a constant switching frequency using space vector modulation (SVM) and tested through numerical simulations. The instantaneous active and reactive powers provided by orthogonal VF positive sequence components are directly controlled. More importantly, this configuration gives quasi-sinusoidal and balanced current under different input voltage conditions without using the power compensation methods. The results of the simulation confirmed the validity of the proposed virtual flux algorithm and demonstrated excellent performance under different input voltage conditions, a complete rejection of disturbances.
\end{abstract}

Copyright () 2019 Institute of Advanced Engineering and Science. All rights reserved.

\section{Corresponding Author:}

Ismail Boukhechem,

Department of Electrical, Electrotechnical Laboratory,

University of August 20 Skikda,

Algeria

Email: sameu25@gmail.com

\section{INTRODUCTION}

Grid-tied three-phase PWM rectifiers are commonly used in numerous industrial applications. This topology has many advantages such as; unity power factor operation, high-quality DC voltage, and low harmonic current distortion.

The voltage oriented control (VOC) and direct power control (DPC) are the most widely used as control methods for the PWM rectifier application. The concept of VOC is simple but requires coordinate transformations and three proportional-integral controllers (PI) [1]. DPC approach imposes a direct tuning for input active and reactive powers by using a predefined switching table. Thus, the digitized signals of the power errors extracted by a hysteresis controller and the angular position of the mains vector voltage are adopted as inputs for this predefined switching table [2][3]. The main deficiencies of DPC are the high and variable switching frequency [4] and the reduced steady-state performance. In order to overcome this backward, several improved DPC have been suggested in the literature to fix and minimize the switching frequency and losses. Hence a vector modulation based on a PI DPC controller (DPC-SVM) has been proposed [5]. On the other hand, a predictive controller based SVM modulation has been developed in [2], which can ensure simultaneously, a constant switching frequency operation and accepts as well as steadystate performance. In this latter, the predictive approach is based on a deadbeat control principle, that can 
calculate the required optimal voltage vector of the rectifier at each switching period Ts, in order to cancel simultaneously the active and reactive power tracking errors at the end of the switching period.

The sensorless control methods offer technical and economic advantages to the system such as simplification, isolation between the power circuit and the control system, reliability, cost-effectiveness and the ability to reduce the number of expensive sensors. The authors in [16] propose a new PDPC control concept based virtual flux that can ensure grid voltage sensorless function for the PWM rectifier, hence regulation of input active and reactive powers and a constant switching frequency operation have been successfully implemented. Furthermore, recently several control strategies based on the VF concept and the SVM modulation have been proposed in the literature, which can to eliminate effectively the power ripples and achieve a constant switching frequency operation simultaneously [16][17][18].

The conventional DPC control performance under unbalanced and/or distorted input voltages has been severely deteriorated, and the input currents are seriously affected by the low order harmonic contents. Researcher's works dealing with the problem of DPC performance under disturbed input voltages are limited, and the proposed concepts suffer many drawbacks, mainly the excessive software burden. Most solutions for improving the performance of three-phase PWM rectifiers are based on the extraction of the positive/negative voltage/current sequences [14][15]. These solutions are complicated and difficult to implement for real-time applications.

The concept of virtual flux (VF) is firstly introduced in the VOC control process, where it was applied to manage the disturbances of the grid voltages [11]. After many control approaches have been developed using the concept of virtual flux (VF) [8][15][19][20], it is worth to mention that it is very popular compared to other sensorless control systems. It has been widely studied and evaluated for different control methods such as direct power control (DPC), VOC control and predictive power control (PDPC) [13][21][22]. The DPC control based virtual flux (VF-DPC) exploits the detected AC line currents and the estimated virtual flux to calculate the input powers. This method offers some advantages such as excellent dynamics, low current THD factor, low sampling frequency and ease of voltage and input powers estimation[12] [13]. The use of a pure integrator induces a DC to offset in the estimated VF. In order to remedy this drawback, the authors in [13][22] proposed an improved method to estimate the VF via a firstorder low-pass filter (FLOP). However, the FLOP filter as well causes magnitude and phase errors [4]. These errors can be canceled by using a flux observer or compensation gain. Several methods for the practical implementation of the Virtual Flux estimation have been proposed, with the aim of avoiding the drift and saturation of the estimated signals. The simplest methods for estimating Virtual Flux is, using analogical or digital filters with phase characteristics designed to emulate integration at the fundamental frequency of the network, but also more advanced, adaptive integration methods. In the aforementioned VF-based methods, the VF space vector is obtained by integrating the voltage space vector. This integration is generally performed via a first-order low-pass filter (FLOP) to avoid the problems of saturation and drift-dc associated with pure integrators [23][25]. However, FLOP filters lead to magnitude and phase errors. Although these errors can be minimized by reducing the cut off frequency of the filter, this reduction leads to a decrease in the filter bandwidth and therefore to a degradation of its dynamics. And for this, the authors [15][26] propose an estimator SOGI exploiting the concept of virtual flux proposed initially by Malinowski [12]. This concept combines the PWM rectifier input filter with a virtual asynchronous machine. Thus the voltages of the network are supposedly induced by a virtual magnetic flux [15][26][27]. Several control algorithms based VF order generalized integrator (SOGI) [23], was configured as a quadratic signal generator and it was presented in [6]. Recent research in [7], presents a combination between adaptive SOGI filter and phase-locked loop to realize a synchronization scheme based on VF [8]. Furthermore, authors in [9] developed a new sensorless VF-PDPC strategy for the PWM rectifier application based on a natural filter integrator (NF-I) combined with an adaptive linear neural filter with a multi-output neural (ADALINE), to ensure that the grid currents emulate the desirable sinusoidal waveform even when the voltage supply is unbalanced and/or harmonized.

The main contribution of this paper is the proposition of a novel virtual flux detection technique incorporated in a predictive direct power control scheme (VF-PDPC) for a three-phase PWM rectifier. The VF algorithm has an open-loop structure and uses the output fundamental orthogonal signals which are obtained directly from estimating the fundamental active and reactive powers. This method provides a quasisinusoidal input current waveforms under different input voltage conditions and achieved good stability, improve the performance of the VF_PDPC.

\section{PREDICTIVE DIRECT POWER CONTROL PRINCIPLE VF-PDPC:}

This section introduced the proposed ac voltage sensorless control algorithm of the PWM rectifier. For removing the ac voltage sensors, the PWM rectifier model is expressed as a function of the estimated VF. The proposed predictive DPC scheme is based on the estimating of the rectifier fundamental virtual flux 
component vector $\varphi_{\alpha \beta}$ using a predictive control algorithm. For this reason, instantaneous fundamentals of active and reactive power estimates and power-source virtual flux $\mathrm{e}_{\alpha \beta}$ are used as input data variables of the predictive control algorithm block as shown in Figure 1.

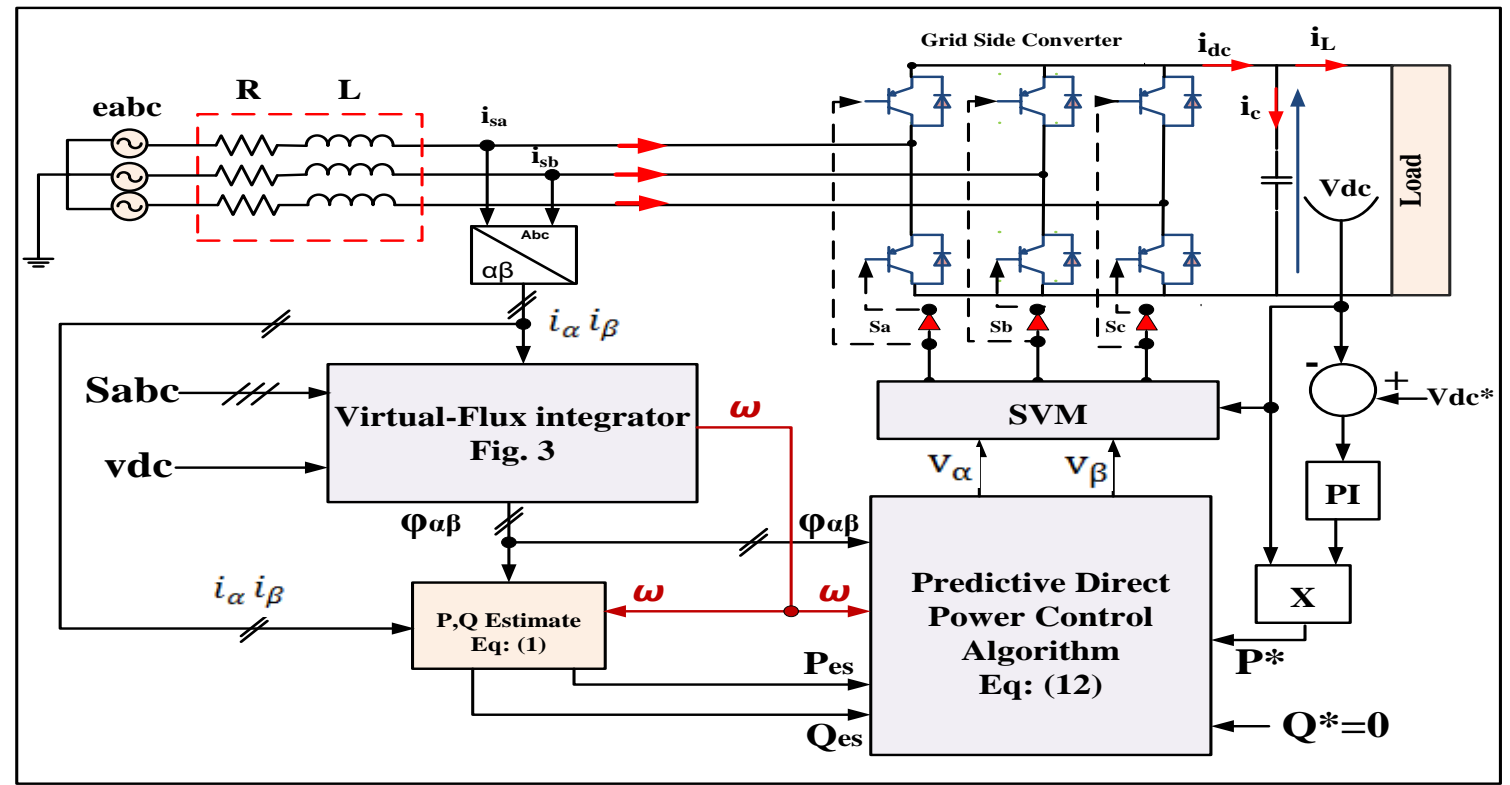

Figure 1. The control diagram of the proposed sensorless VF-PDPC of a PWM rectifier

At the beginning of each switching period Ts, the rectifier average virtual flux vector $\varphi_{\alpha \beta}$, which allows cancellation of instantaneous active and reactive power tracking errors at the end of the switching period, is computed. The SVM technique is Then used to generate a sequence of switching states, giving a sequence of adjacent rectifier vectors. To achieve this objective control with the constant switching frequency, the estimated input of active and reactive powers of the three-phase PWM rectifier in the stationary reference frame $\alpha-\beta$ and for a balanced three-phase system are defined as:

$$
\left\{\mathrm{P}_{\mathrm{es}}=\omega\left(\varphi_{\alpha} * \mathrm{i}_{\beta}-\varphi_{\beta} * \mathrm{i}_{\alpha}\right)\right.
$$

\subsection{VF-PDPC Relations}

The converter can be expressed in $\alpha, \beta$ reference by the following equations [9] [29]:

$\left[\begin{array}{l}\mathrm{e}_{\alpha} \\ \mathrm{e}_{\beta}\end{array}\right]=R\left[\begin{array}{l}\mathrm{i}_{\alpha} \\ \mathrm{i}_{\beta}\end{array}\right]+L \frac{d}{d t}\left[\begin{array}{l}\mathrm{i}_{\alpha} \\ \mathrm{i}_{\beta}\end{array}\right]+\left[\begin{array}{l}\mathrm{v}_{\alpha} \\ \mathrm{v}_{\beta}\end{array}\right]$

In VF theory, the grid voltages of the AC side, coupling impedances are assumed to be a virtual AC motor. Therefore, the components of FV in the frame $(\alpha, \beta)$ can be expressed:

$\left[\begin{array}{l}\varphi_{\alpha} \\ \varphi_{\beta}\end{array}\right]=\int\left[\begin{array}{l}\mathrm{e}_{\alpha} \\ \mathrm{e}_{\beta}\end{array}\right] d t$ [6]:

On the other hand, under ideal network conditions, grid voltages can be estimated at steady state as

$$
\left[\begin{array}{l}
\mathrm{e}_{\alpha} \\
\mathrm{e}_{\beta}
\end{array}\right]=\left[\begin{array}{c}
-\omega * \varphi_{\beta} \\
\omega * \varphi_{\alpha}
\end{array}\right]
$$

From (1) and (4), the VF components are estimated as:

$\left[\begin{array}{l}\varphi_{\alpha} \\ \varphi_{\beta}\end{array}\right]=\int\left(R\left[\begin{array}{l}i_{\alpha} \\ i_{\beta}\end{array}\right]+\left[\begin{array}{l}\mathrm{v}_{\alpha} \\ \mathrm{v}_{\beta}\end{array}\right]\right) d t+L\left[\begin{array}{l}\mathrm{i}_{\alpha} \\ \mathrm{i}_{\beta}\end{array}\right]$

It should be noted that $\mathrm{R}$ is included in the estimation process VF given by (6). The input voltages of the rectifier are calculated according to the switching status of three-phase PWM rectifier:

$\left[\begin{array}{c}\mathrm{v}_{\alpha} \\ \mathrm{v}_{\beta}\end{array}\right]=\frac{V_{d c}}{3}\left[\begin{array}{c}2 \mathrm{~S}_{\alpha}-\mathrm{S}_{\mathrm{b}}-\mathrm{S}_{\mathrm{c}} \\ \sqrt{3}\left(\mathrm{~S}_{\beta}-\mathrm{S}_{\mathrm{c}}\right)\end{array}\right]$

$\left[\begin{array}{l}P_{e s} \\ Q_{e s}\end{array}\right]=\omega\left[\begin{array}{cc}\varphi_{\alpha} & -\varphi_{\beta} \\ \varphi_{\alpha} & \varphi_{\beta}\end{array}\right]\left[\begin{array}{l}i_{\alpha} \\ i_{\beta}\end{array}\right]$

where $\varphi_{\alpha \beta}=\left[\varphi_{\alpha} \varphi_{\beta}\right]^{\mathrm{T}}$ and $\mathrm{i}_{\alpha \beta_{\mathrm{h}}}=\left[\mathrm{i}_{\alpha} \mathrm{i}_{\beta}\right]^{\mathrm{T}}$ being the estimated flux and line current vectors respectively in a static $\alpha-\beta$ frame. 
Assuming that the sampling period $T_{s}$ is very small compared to the estimated flux period, the components of $\varphi_{\alpha \beta}$ are assumed to be constant during the switching period $\varphi_{\alpha \beta}(\mathrm{k}+1)=\varphi_{\alpha \beta}(\mathrm{k})$.

As a result, the variation of the active and reactive powers between two successive sampling instants can be expressed as follows:

$\left[\begin{array}{l}P_{e s}(k+1)-P_{e s}(k) \\ Q_{e s}(k+1)-Q_{e s}(k)\end{array}\right]=\omega\left[\begin{array}{cc}\varphi_{\alpha}(k) & -\varphi_{\beta}(k) \\ \varphi_{\alpha}(k) & \varphi_{\beta}(k)\end{array}\right]\left[\begin{array}{c}i_{\alpha}(k+1)-i_{\alpha}(k) \\ i_{\beta}(k+1)-i_{\beta}(k)\end{array}\right]$

The differential equations of the PWM rectifier can be expressed as:

$L \frac{d}{d t}\left[\begin{array}{l}\mathrm{i}_{\alpha}(\mathrm{t}) \\ \mathrm{i}_{\beta}(\mathrm{t})\end{array}\right]=\left[\begin{array}{c}-\omega * \varphi_{\alpha}(\mathrm{t}) \\ \omega * \varphi_{\beta}(\mathrm{t})\end{array}\right]-\left[\begin{array}{l}\mathrm{v}_{\alpha}(\mathrm{t}) \\ \mathrm{v}_{\beta}(\mathrm{t})\end{array}\right]-R\left[\begin{array}{l}\mathrm{i}_{\alpha}(\mathrm{t}) \\ \mathrm{i}_{\beta}(\mathrm{t})\end{array}\right]$

$\left[\begin{array}{c}\mathrm{i}_{\alpha}(\mathrm{k}+1)-\mathrm{i}_{\alpha}(\mathrm{k}) \\ \mathrm{i}_{\beta}(\mathrm{k}+1)-\mathrm{i}_{\beta}(\mathrm{k})\end{array}\right]=\frac{T_{S}}{L}\left(\left[\begin{array}{c}-\omega * \varphi_{\alpha}(\mathrm{k}) \\ \omega * \varphi_{\beta}(\mathrm{k})\end{array}\right]+\left[\begin{array}{c}\mathrm{v}_{\alpha}(\mathrm{k}) \\ \mathrm{v}_{\beta}(\mathrm{k})\end{array}\right]\right)$

The variation of the active and reactive powers during a switching period $T_{s}$ is given as follows:

$\left[\begin{array}{c}\mathrm{P}_{\mathrm{es}}(\mathrm{k}+1)-\mathrm{P}_{\mathrm{es}}(\mathrm{k}) \\ \mathrm{Q}_{\mathrm{es}}(\mathrm{k}+1)-\mathrm{Q}_{\mathrm{es}}(\mathrm{k})\end{array}\right]=\omega\left[\begin{array}{cc}\varphi_{\alpha}(\mathrm{k}) & -\varphi_{\beta}(k) \\ \varphi_{\alpha}(\mathrm{k}) & \varphi_{\beta}(k)\end{array}\right] * \frac{T_{s}}{L}\left(\left[\begin{array}{c}-\omega * \varphi_{\alpha}(\mathrm{k}) \\ \omega * \varphi_{\beta}(\mathrm{k})\end{array}\right]+\left[\begin{array}{c}\mathrm{v}_{\alpha}(\mathrm{k}) \\ \mathrm{v}_{\beta}(\mathrm{k})\end{array}\right]\right)$

$\left[\begin{array}{c}\mathrm{v}_{\alpha}(\mathrm{k}) \\ \mathrm{v}_{\beta}(\mathrm{k})\end{array}\right]=\omega\left[\begin{array}{c}\varphi_{\alpha}(\mathrm{k}) \\ \varphi_{\beta}(\mathrm{k})\end{array}\right]-\left[\begin{array}{cc}\mathrm{R} & -\omega \mathrm{L} \\ \omega \mathrm{L} & \mathrm{R}\end{array}\right]\left[\begin{array}{c}\mathrm{i}_{\alpha}(\mathrm{t}) \\ \mathrm{i}_{\beta}(\mathrm{t})\end{array}\right]-\frac{L}{T_{S} \omega\left\|\varphi_{\alpha \beta}\right\|^{2}}\left[\begin{array}{cc}-\varphi_{\beta}(\mathrm{k}) & \varphi_{\alpha}(k) \\ \varphi_{\alpha}(\mathrm{k}) & \varphi_{\beta}(k)\end{array}\right]\left[\begin{array}{l}\mathrm{P}_{\mathrm{es}}(\mathrm{k}+1)-\mathrm{P}_{\mathrm{es}}(\mathrm{k}) \\ \mathrm{Q}_{\mathrm{es}}(\mathrm{k}+1)-\mathrm{Q}_{\mathrm{es}}(\mathrm{k})\end{array}\right]$

\subsection{Proposed Algorithm for Filtering Components of the VF}

As mentioned in previous researches [8][12][24], a virtual flux, $\varphi$, can be obtained by integrating the output voltage of the converter, $\mathrm{V}_{\text {conv }}$. Using basic modulation knowledge, the output voltage of the converter can be easily estimated by multiplying the converter pulse width modulation reference signal, $\mathrm{m}_{\text {ref }}, \alpha \beta$ by the intermediate circuit voltage. However, the voltage drop caused by the conduction losses of the converter and the primary filter inductance, represented by the equivalent resistance R, must be taken into account to find the output voltage of the converter before carrying out the integration. Considering that the flux calculation will be based on the stationary reference $\alpha, \beta$ the virtual flux can be calculated as shown in the equation (5). The virtual flux concept has been developed for a better estimate of instantaneous active and reactive powers in AC-free sensor operation. The use of an ideal integrator for calculating the virtual flux produces a DC offset, which represents the average value of the signal.

The VF estimation process is performed through a pure integrator. This estimator leads to easy and simple estimation, but saturated output with dc offset is observed. The discrete form of $\varphi_{\alpha-i}$ and $\varphi_{\beta-i}$ under non-ideal conditions can be written as:

$$
\left[\begin{array}{l}
\varphi_{\alpha-\mathrm{i}}(\mathrm{t}) \\
\varphi_{\beta-\mathrm{i}}(\mathrm{t})
\end{array}\right]=\left[\begin{array}{l}
\varphi_{1} \sin \left(\omega_{1} \mathrm{t}+\theta_{1}\right) \\
\varphi_{1} \cos \left(\omega_{1} \mathrm{t}+\theta_{1}\right)
\end{array}\right]+\left[\begin{array}{l}
\mathrm{A}_{0} \\
\mathrm{~B}_{0}
\end{array}\right]+\sum_{n=2}^{\infty}\left[\begin{array}{l}
\varphi_{\mathrm{n}} \sin \left(\omega_{\mathrm{n}} \mathrm{t}+\theta_{\mathrm{n}}\right) \\
\varphi_{\mathrm{n}} \cos \left(\omega_{\mathrm{n}} \mathrm{t}+\theta_{\mathrm{n}}\right)
\end{array}\right]
$$

where $\varphi_{\mathrm{n}}$ is the magnitude of the nth term, $\omega_{\mathrm{n}}$ its pulsation, $\theta \mathrm{n}$ its initial phase. $\mathrm{A}_{0}$ and $\mathrm{B}_{0}$ are, respectively, the dc offsets of $\varphi_{\alpha-\mathrm{i}}$ and $\varphi_{\beta-\mathrm{i}} \cdot \varphi_{1}$ is the magnitude of fundamental components of the $\varphi_{\alpha-\mathrm{i}}$ and $\varphi_{\beta-\mathrm{i}}$, While the fundamental virtual flux value is expressed as follows:

$$
\left[\begin{array}{l}
\varphi_{\alpha}(t) \\
\varphi_{\beta}(t)
\end{array}\right]=\left[\begin{array}{l}
\varphi_{1} \sin \left(\omega_{1} t+\theta_{1}\right) \\
\varphi_{1} \cos \left(\omega_{1} t+\theta_{1}\right)
\end{array}\right]
$$

The continuous shift induced by the pure integrator will be easily eliminated using our new adaptive algorithm. The new idea in the estimator process is to obtain an appropriate decomposition of the VF $\alpha-\beta$ components obtained from the pure integrator $\varphi_{\alpha \beta-i}$ and to extract their fundamental components. Thus, these components will be written in a form appropriate to be learned by the adaptive algorithm. Our algorithm is illustrated by figure 2 which shows how to decompose the resulting signal from pure integrator.

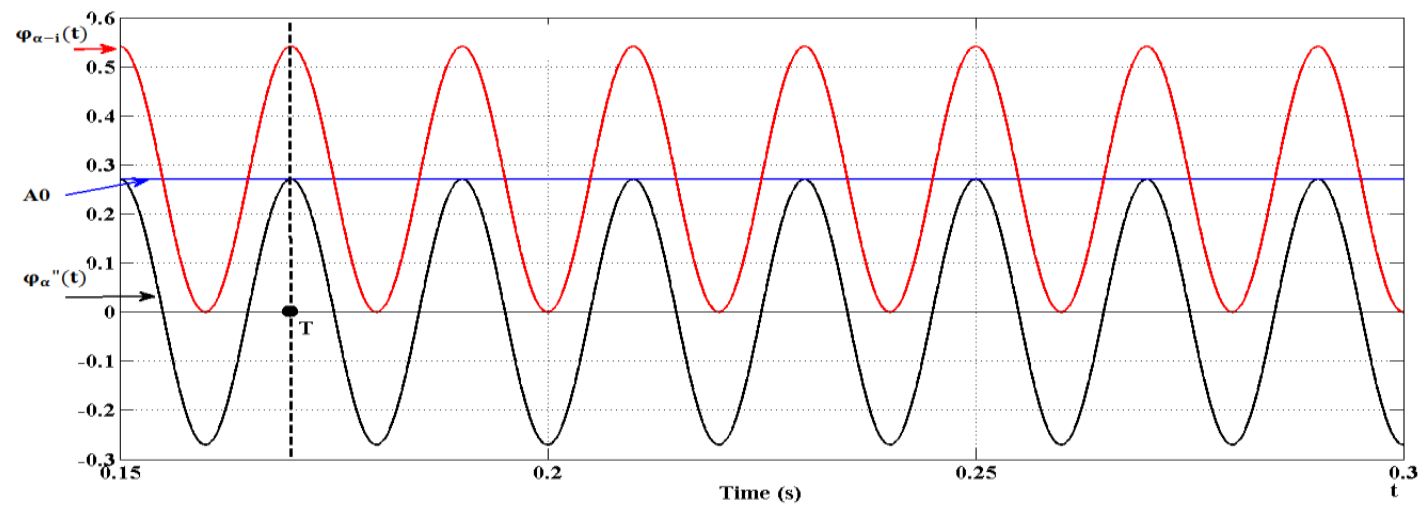

Figure 2. Sinusoidal quantities 
Consider a magnitude represented by the function:

$u(t)=u_{1} \cos \left(\omega_{0} t\right)$

and the same function with an offset still called continuous component:

$\varphi_{\alpha-\mathrm{i}}(\mathrm{t})=A_{0}+\varphi_{\alpha}{ }^{\prime \prime} \cos (\omega t)$

This quantity is represented in Figure 2. Its period is $T=\frac{2 \pi}{\omega}$, its frequency is $f=\frac{\omega}{2 \pi}$ and its amplitude is $\varphi_{\alpha}$ " or $2 \varphi_{\alpha} "$ so, its average is $A_{0}$.

We can consider that the signal $\mathrm{u} 1$ as the required virtual flux, Where the equation becomes:

$\varphi_{\alpha}^{\prime \prime} \cos (\omega t)=\varphi_{\alpha-\mathrm{i}}(\mathrm{t})-A_{0}$

Where:

$A_{0}=<\varphi_{\alpha-\mathrm{i}}(\mathrm{t})>=\frac{1}{T} \int_{0}^{T} u(t) d t$

The proposed algorithm is composed of the VF estimator based on a pure integrator in series with an adaptive block which calculates the average value of the latter. As we can see in Fig. 3. In mathematics, the course on the integral being done and the definition of the average value is given, one specifies the definition of the average value $\left\langle\varphi_{\alpha \beta-i}\right\rangle$ of a periodic function $\mathrm{f}$, of period $\mathrm{T}$, by the equation (18). So to obtain a symmetrical virtual flux without the DC value, we apply the equation (17).

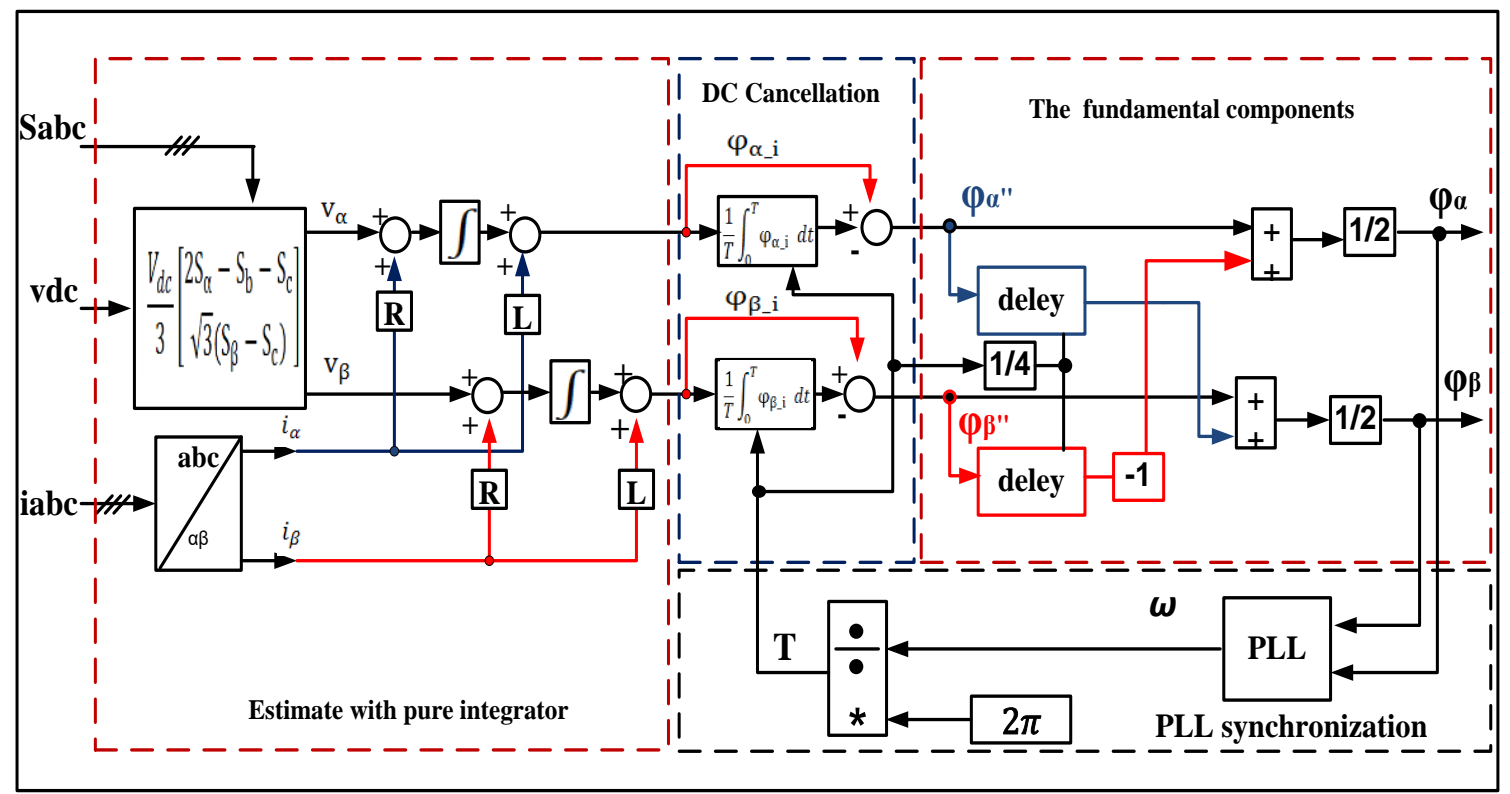

Figure 3. Proposed Virtual flux estimation block (Fp)

After canceling the DC value the relationship becomes as follows:

$$
\left[\begin{array}{l}
\varphi_{\alpha^{\prime \prime}}(\mathrm{t}) \\
\varphi_{\beta^{\prime \prime}}(\mathrm{t})
\end{array}\right]=\left[\begin{array}{l}
\varphi_{1} \sin \left(\omega_{1} \mathrm{t}+\theta_{1}\right) \\
\varphi_{1} \cos \left(\omega_{1} \mathrm{t}+\theta_{1}\right)
\end{array}\right]+\sum_{n=2}^{\infty}\left[\begin{array}{l}
\varphi_{\mathrm{n}} \sin \left(\omega_{\mathrm{n}} \mathrm{t}+\theta_{\mathrm{n}}\right) \\
\varphi_{\mathrm{n}} \cos \left(\omega_{\mathrm{n}} \mathrm{t}+\theta_{\mathrm{n}}\right)
\end{array}\right]
$$

It is clear from this relationship that the virtual flux is always affected by the harmonic and imbalance components. Accordingly, The delayed signal cancellation (DSC) method [28] is used to separate the positive and negative sequences under unbalanced grid fault conditions, based on the following expressions:

$$
\left[\begin{array}{l}
\varphi_{\alpha}(\mathrm{t}) \\
\varphi_{\beta}(\mathrm{t})
\end{array}\right]=\frac{1}{2}\left[\begin{array}{l}
\varphi_{\alpha^{\prime \prime}}(\mathrm{t})-\mathrm{j} \varphi_{\beta^{\prime \prime}}(\mathrm{t}-\mathrm{T} / 4) \\
\varphi_{\beta^{\prime \prime}}(\mathrm{t})+\mathrm{j} \varphi_{\alpha^{\prime \prime}}(\mathrm{t}-\mathrm{T} / 4)
\end{array}\right]
$$

Where $\mathrm{T}$ is the period of the grid voltage.

\section{SIMULATION RESULTS}

To test the validity of the proposed VF_PDPC strategy, several simulation tests were conducted under different operating conditions. The simulations of the overall system which is presented in Fig. 1 was performed using MATLAB-Simulink environment. The used simulation parameters are listed in Table 1 . During simulations, This control ensures full rejection of mains disturbances and the DC link voltage is controlled at $180 \mathrm{~V}$. 


\begin{tabular}{lc}
\multicolumn{2}{c}{ Table 1. Parameters of the power circuit } \\
\hline Sampling period Ts & $20 \mu \mathrm{S}$ \\
The resistance of reactors R & $0.56[\Omega]$ \\
Inductance of reactors L & $19.5[\mathrm{mH}]$ \\
dc-bus capacitor C & $1100 \mu \mathrm{F}$ \\
Load Resistance $R L$ & $68.6[\Omega]$ \\
The line to line ac voltage $E$ and frequency $f$ & $85 \mathrm{~V} \mathrm{rms}, 50 \mathrm{~Hz}$ \\
dc-bus voltage $V d c$ & $180 \mathrm{~V}$ \\
Switching frequency & $7500 \mathrm{~Hz}$ \\
\hline
\end{tabular}

\subsection{Startup Performances}

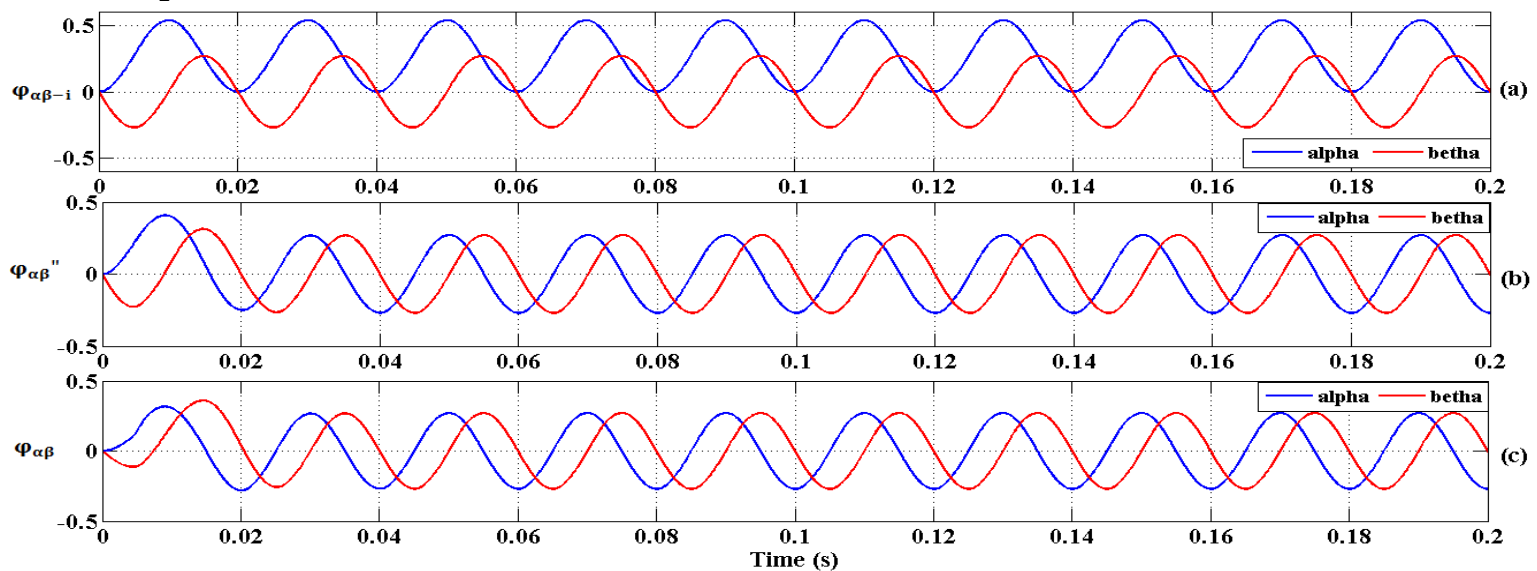

Figure 4. VF $\alpha-\beta$ components estimation.. (a) VF at start-up when the pure integrator $\varphi_{\alpha \beta-i}$. (b) FV DC value cancellation $\varphi_{\alpha \beta}$ " (c) fundamental $\operatorname{VF} \varphi_{\alpha \beta}$

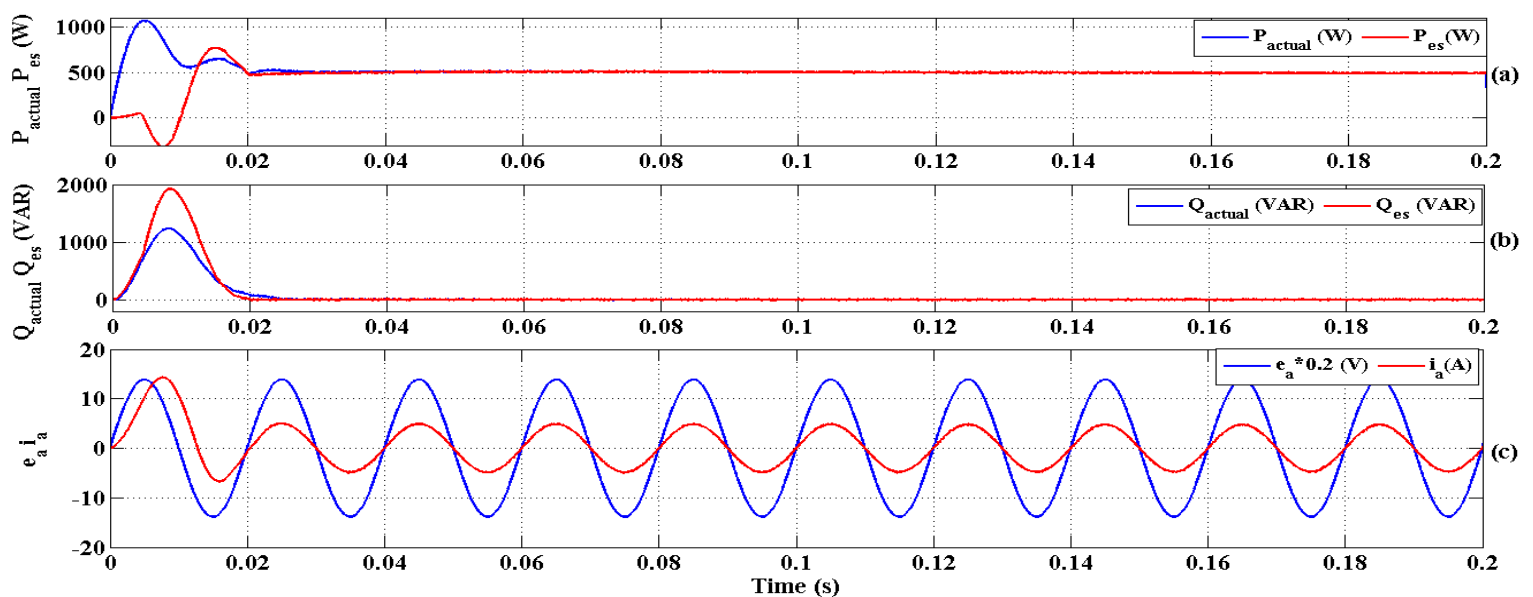

Figure 5. Performance of the proposed Filter Fp. (a) Actual and estimated active powers. (b) Actual and estimated reactive powers. (c) Actual grid voltage and current (phase a)

Figure 4 shows the start-up VF estimation performance of the pure integrator and the proposed filter Fp. From Figure 4 (a), the estimated component $\alpha$ of VF using pure integrator contains a continuous shift. On the other hand, the application of the proposed filter Fp removing the DC offset from the estimated VF $\alpha$ is shown in Figure 4 (b). The transient time is about one mains cycle. Figure 4 (c) shows that the estimated fundamental virtual flux $\varphi_{\alpha \beta}$ is stable with very short response time.

Figure 5 (a) and Figure 5 (b) illustrate, respectively, the actual and estimated active and reactive power at start-up. From these results, due to the fast estimation of the VF using Fp observer, the actual active and reactive powers exhibit small fluctuations and overshoots. Consequently, acceptable fluctuations and overshoots occur in the actual currents of the AC line as shown in Figure 5 (c).

It can be also noted that the transient response and the computational time of the fundamental virtual flux is fast and well-damped, due to the proposed estimator which realizes a virtual flux estimation without voltage sensors with a response time of $0.02 \mathrm{~s}$. Based on previous findings, the temporal response of the proposed filter Fp is considered the best compared to other estimation methods. 


\subsection{Responses in various grid voltage conditions}

Three grid voltage conditions are applied. Initially, a voltage imbalance of $30 \%$ is created on phase ea. In the next interval, the imbalance of $20 \%$ and 7 th order harmonic of $20 \%$, is also included. Finally, the worst case of grid voltages, the harmonics 5 and 7 with an amplitude of $20 \%$ are applied.

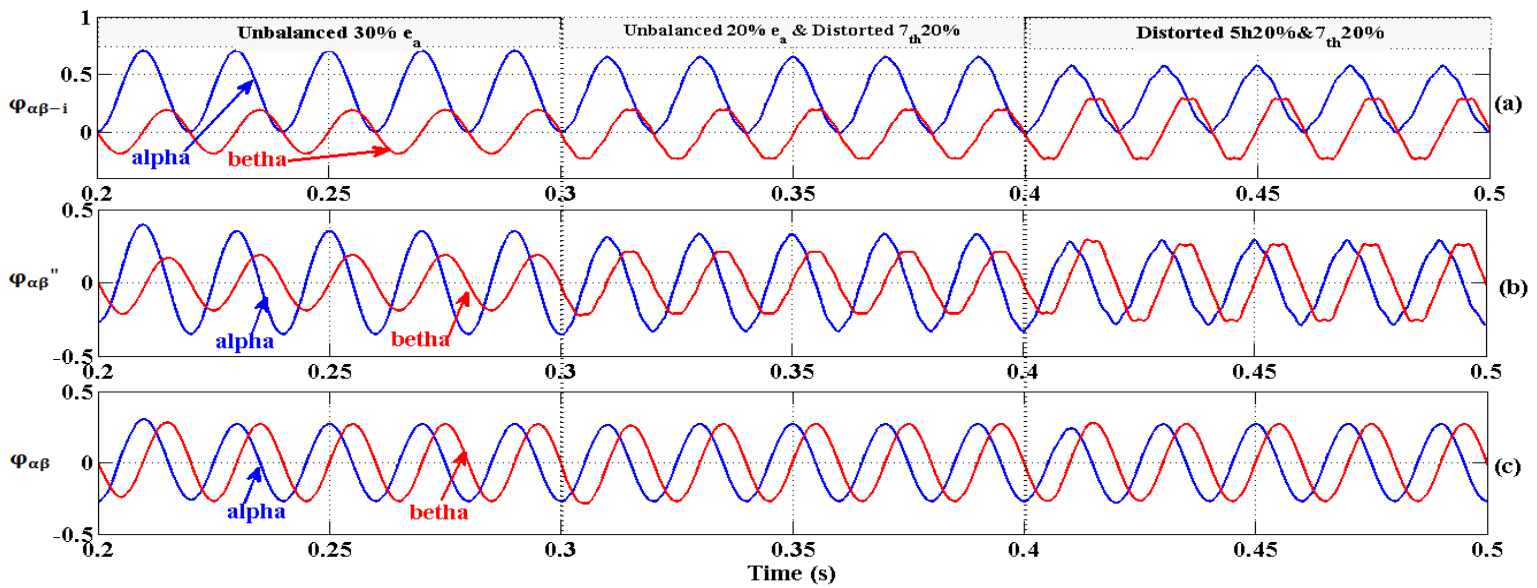

Figure 6. VF $\alpha-\beta$ components estimation under different conditions grid voltages. (a) VF of pure integrator $\varphi_{\alpha \beta-i}$. (b) FV DC value cancellation $\varphi_{\alpha \beta} "$ (c) fundamental $\operatorname{VF} \varphi_{\alpha \beta}$

Fig. 6 shows the performance of the proposed Fp filter under different grid voltage conditions. The estimated VF with pure integrator introduces a continuous shift in the $\alpha$ axis component of VF [as shown in Figure 6 (a)]. Figure 6 (b) shows The DC offset is canceled successfully without introducing phase shift, But the imbalance and the distorted has not been removed. Figure 6 (c) illustrates the effectiveness of this proposed $\mathrm{Fp}$, the fundamental virtual flux estimated by this integrator remains stable in all studied cases. Again and according to the previous results, this integrator proves that it is very effective also with the deformed grid.

\subsection{Frequency variation}

The entire virtual flux estimator dynamic performance is tested by increasing the frequency from $\mathrm{f}=50 \mathrm{~Hz}$ to $\mathrm{f}=58.02 \mathrm{~Hz}$. The result is shown in Fig. 7 .

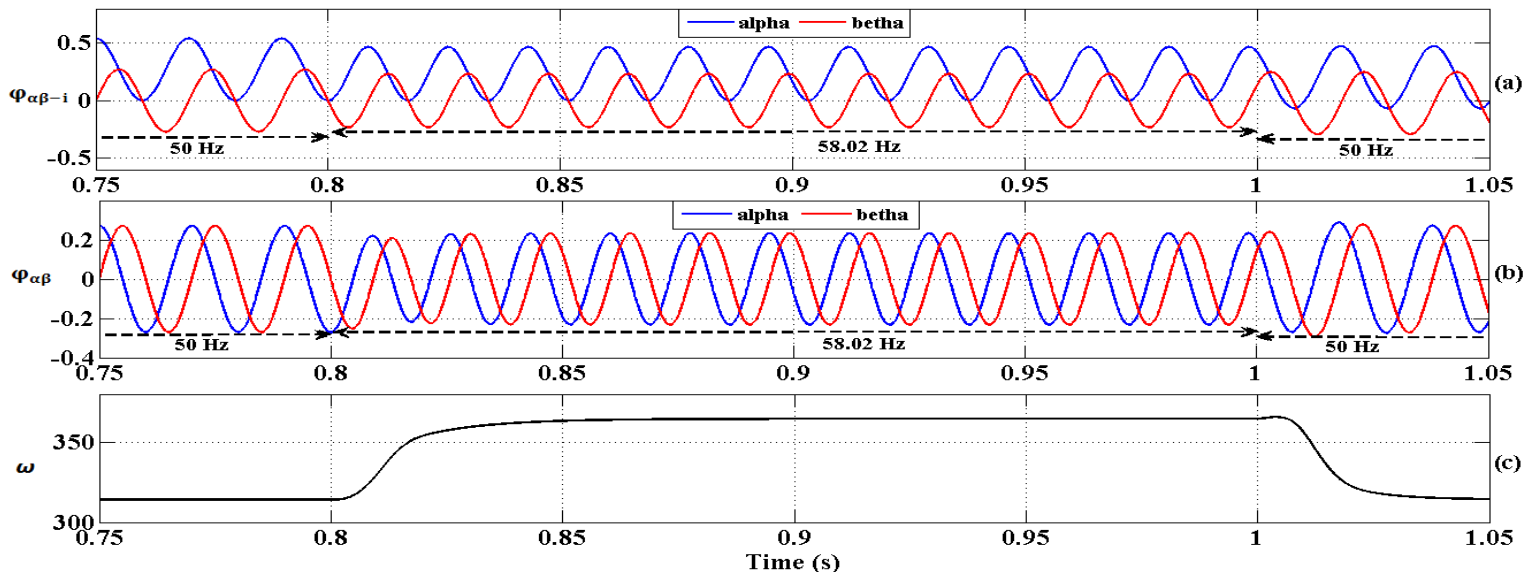

Figure 7. Virtual flux when grid frequency changes from $\mathrm{f}=50 \mathrm{~Hz}$ to $58.02 \mathrm{~Hz}$ : (a) VF of pure integrator $\varphi_{\alpha \beta-i}$ (b) VF fundamental component $\varphi_{\alpha \beta}$ (c) Estimated angular frequency 


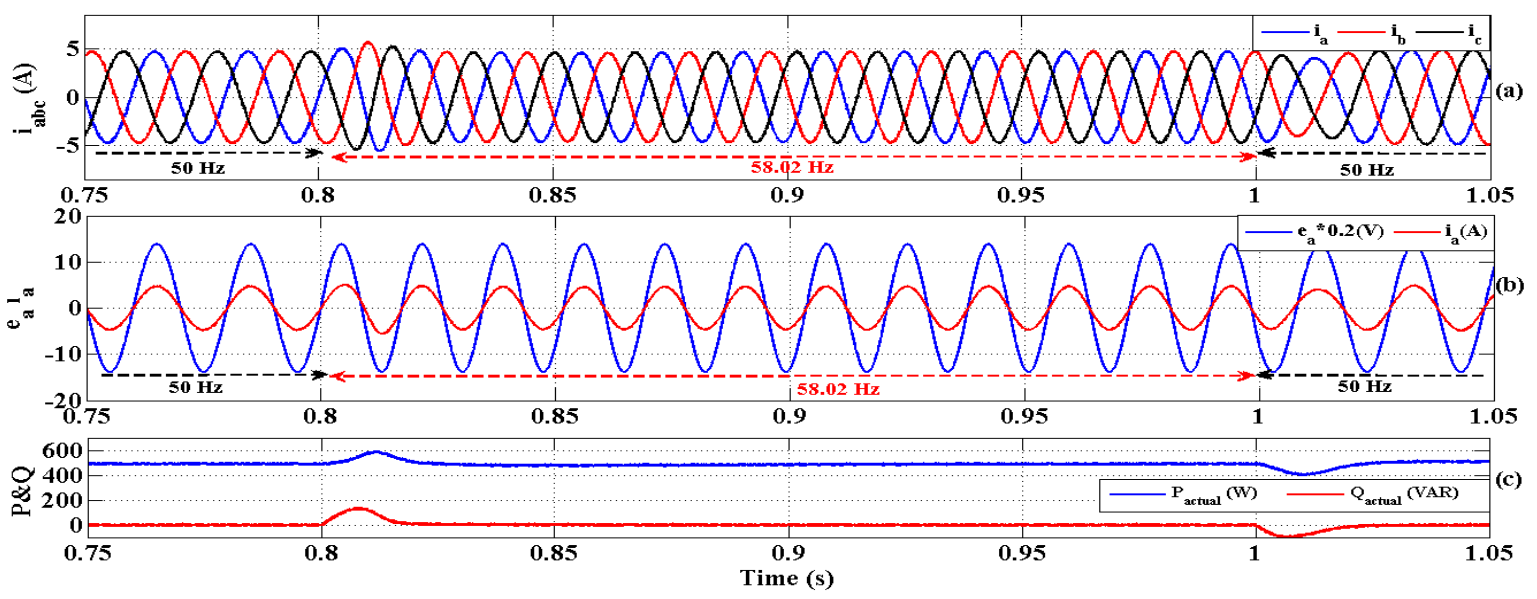

Figure 8. Performance of proposed methods when grid frequency changes (a) grid current (b) grid voltage and current (c) active and reactive power

The grid currents are presented in Figure 8(a). Due to the grid frequency change, it clearly noted from the waveforms that the line current is sinusoidal and balanced. Also the rectifier function under the unity power factor.

As can be seen in Figures 7 and 8, the proposed method shows good performance during an increase in frequency from 50 to $58.02 \mathrm{~Hz}$.

\subsection{Comparative study between the proposed filter Fp and the DSOGI}

In this test, the SOGI estimator and the proposed estimator (Fp) are optimally tuned. Moreover, the two estimators are simulated under the same conditions. Criterions taken into account in the evaluation process of these two techniques are the speed of convergence, stability and calculation time.

A first comparison test between the two estimators in terms of convergence speed is performed. the results obtained are shown in Figure 9. During this test, the reference of the DC bus voltage is kept constant $\mathrm{Vdc}=180 \mathrm{~V}$ and $\mathrm{Rch}=68.6 \Omega$

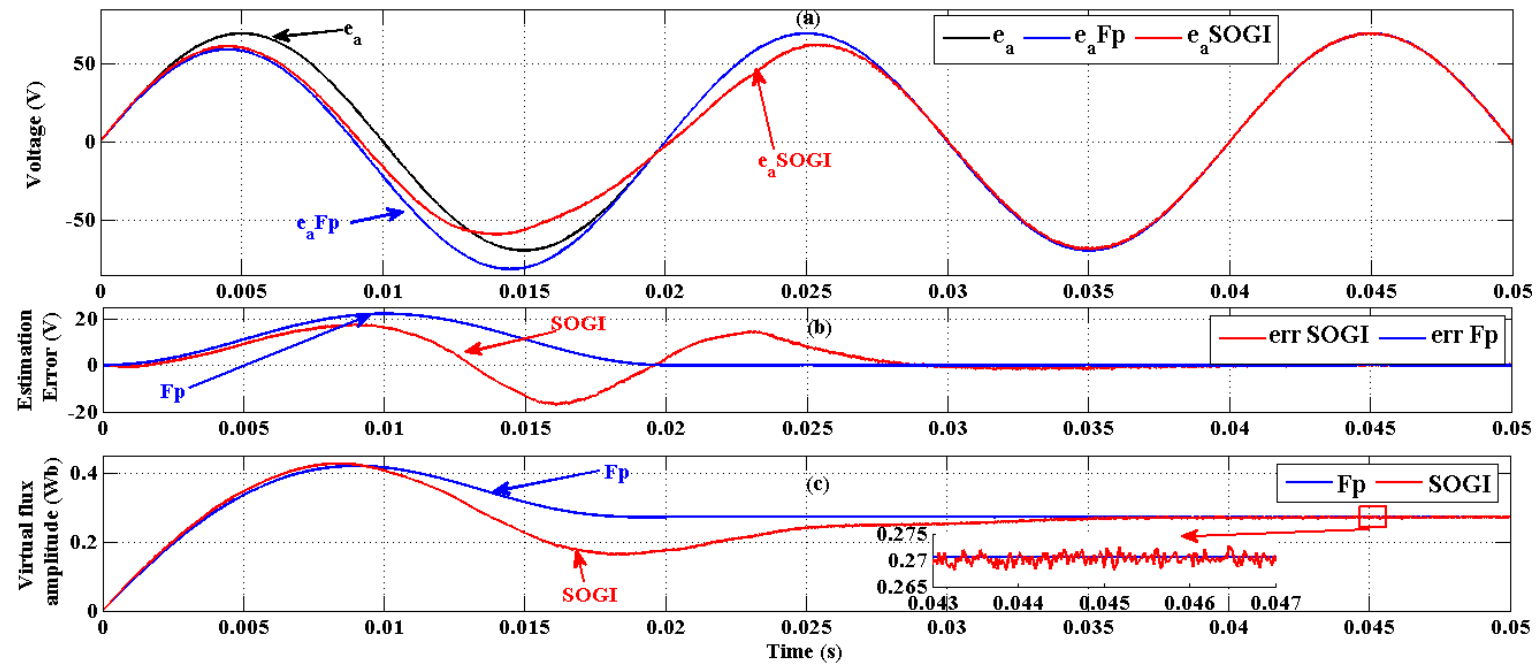

Figure 9. Comparison between the proposed estimator and SOGI (a) measured voltage ea estimated voltage (ea_Fp, ea_SOGI) (b) estimation error (c) the estimated flux amplitude

Figure 9 (a) shows the actual grid voltage $e_{a}$ and the estimated voltages $e_{a}$ Fp and $e_{a}$ SOGI respectively provided by the proposed estimator and SOGI. The corresponding estimation errors are shown in Figure 9 (b). Figure 9 (c) shows the estimated virtual flux amplitude. We deduce from these results that the proposed estimator converges more rapidly than the SOGI estimator. Figure 9 (c) shows that the flux estimated by the proposed estimator is more stable and fast, the flux of the SOGI also contains fluctuation which appears in the zoom of Figure 9 (c). 

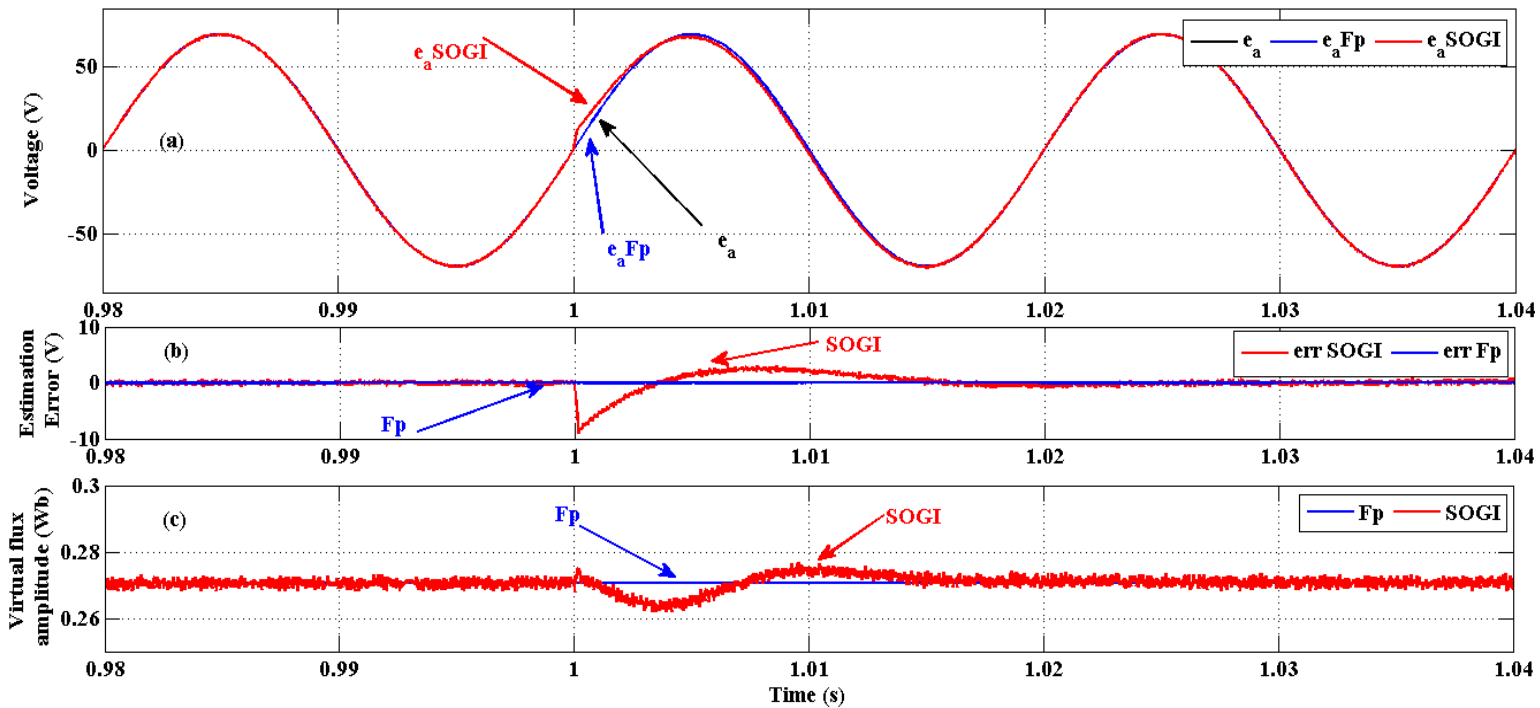

Figure 10. performance comparison for Vdc variation (a) measured voltage ea estimated voltage (ea_Fp, ea_SOGI) (b) estimation error (c) the estimated flux amplitude

A second comparison test between the two estimation methods is performed for a variation of the $\mathrm{Vdc}_{\mathrm{ref}}$ voltage. The results obtained are shown in Fig. 8 for this test $\mathrm{R}_{\mathrm{ch}}=68.6 \Omega$. at the instant $\mathrm{t}=1 \mathrm{~s}$, a variation of $20 \mathrm{~V}$ is applied to the reference voltage ( $\mathrm{Vdc}_{\text {ref }}$ goes from $180 \mathrm{~V}$ to $200 \mathrm{~V}$ ). Figure 10 (a) shows the actual network voltage $e_{a}$ and the estimated voltages $e_{a} F p$ and $e_{a}$ SOGI provided respectively by the proposed estimator and SOGI. The corresponding estimation errors are shown in Figure 10 (b). Figure 10 (c) shows the estimated virtual flux amplitude. From these figures, it is clear that the proposed estimator is not affected by the variation of $\mathrm{Vdc}_{\text {ref }}$ compared to the SOGI estimator where an estimation error has occurred. In the case of the proposed estimator method, all the quantities used in the estimation process are processed. This allowed robust estimation during the transient caused by Vdc variation. From these two tests, it can be concluded that the proposed estimator has a higher speed of convergence and better robustness with a very small computation time, compared to the SOGI estimator.

\subsection{Transient Responses simulated with several grid voltage conditions}

In this test, we will evaluate the performance of the proposed VF_PDPC under unbalanced and harmonized supply voltage conditions. Figure 11 show the behaviour of the proposed VF_PDPC approach under unbalanced sinusoidal input voltages applied at $0.8 \mathrm{~s}\left(\mathrm{e}_{\mathrm{a}}=+25 \%\right.$ and $\mathrm{e}_{\mathrm{c}}=-15 \%$ with respect to $\mathrm{e}_{\mathrm{b}}$ as shown in Figure 11 (a)). The application of the proposed VF_DPC gives balanced and nearly sinusoidal waveforms for the input currents (THD $=1.23 \%$ ) as shown in Figure $11(b)$.

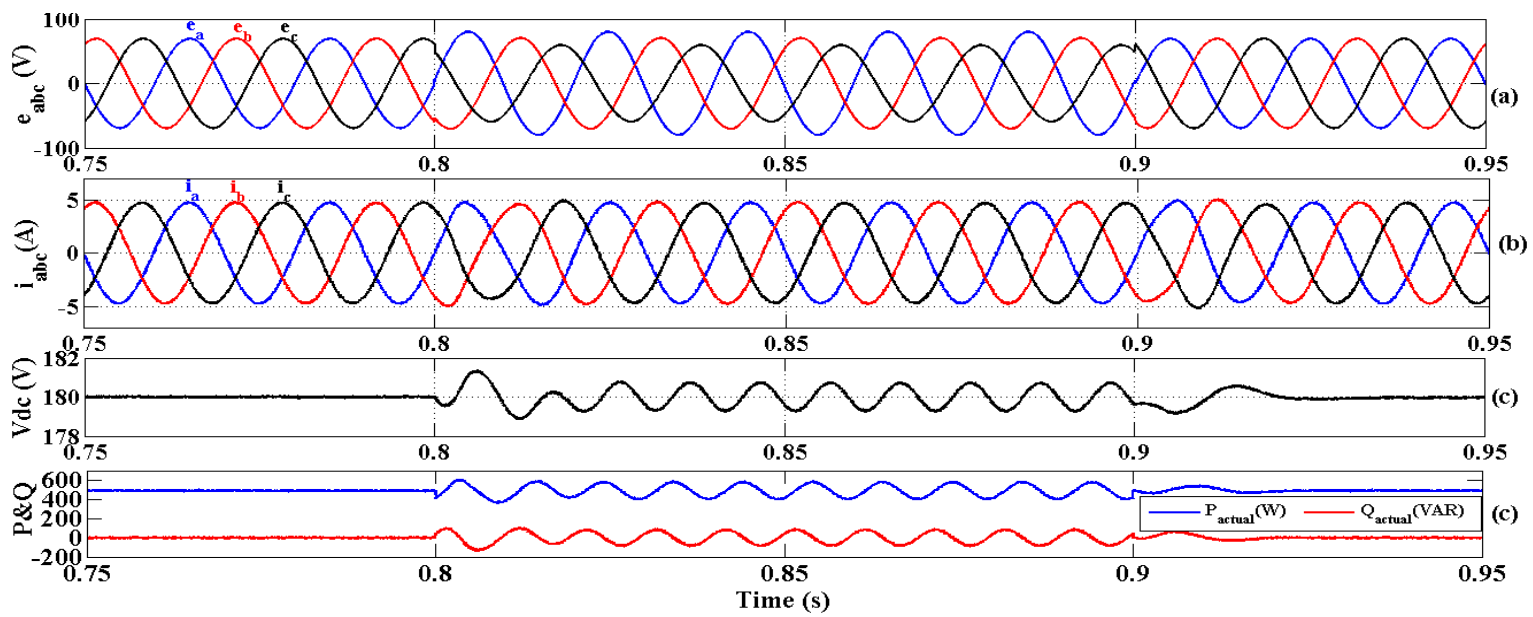

Figure 11. Simulation results for the proposed VF_PDPC of PWM rectifier under unbalanced input voltages (a) grid voltage (b) grid current (c) DC voltage (d) actual active and reactive power 
The monitored powers and DC bus voltage are kept very close to their references as shown in Figure 11 (c) and (d). Figure11 (d) shows that the actual powers follow adequately the imposed references and the oscillations around the average value of the real power and the DC voltage have resulted from the negative part of the input voltages, and its frequency is equal to $2 * \omega$

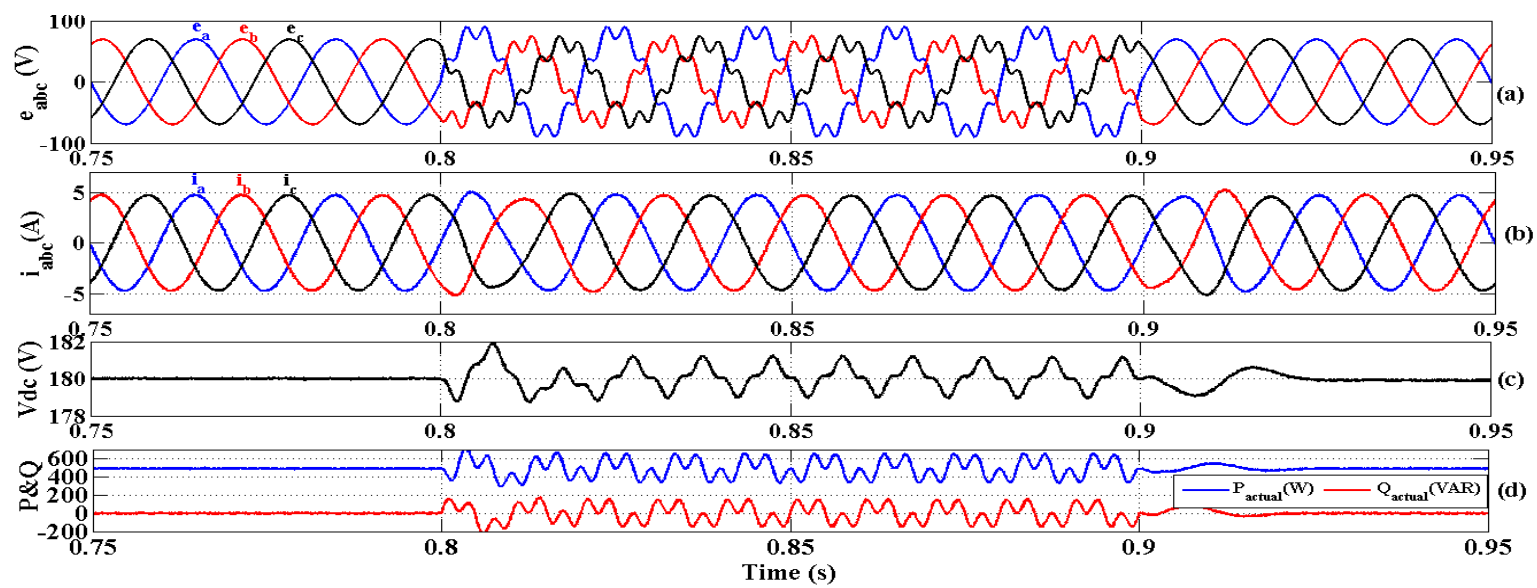

Figure 12. Simulation results for the proposed VF_PDPC of PWM rectifier under unbalanced and distorted Input voltages with 7 th harmonic (a) grid voltage (b) grid current

Simulation results of grid-tied three-phase PWM rectifier operation under asymmetric and distorted input voltages for the proposed control VF_PDPC_SVM are shown in Figure 12, respectively. In this test, the seventh harmonic voltage component of $25 \%$ is superposed on unbalanced sinusoidal input voltages $\left(\mathrm{e}_{\mathrm{a}}=+\right.$ $25 \%$ with respect to $e_{b}$ and $e_{c}$ see Figure 12 (a)). The proposed VF_PDPC also guarantees quasi-sinusoidal balanced input current waveforms (THD $=1.42 \%$ ), as shown in Figure 12 (b). Figure 12 (c) and (d) show that the controlled powers and the DC link voltage are kept very close to their references.

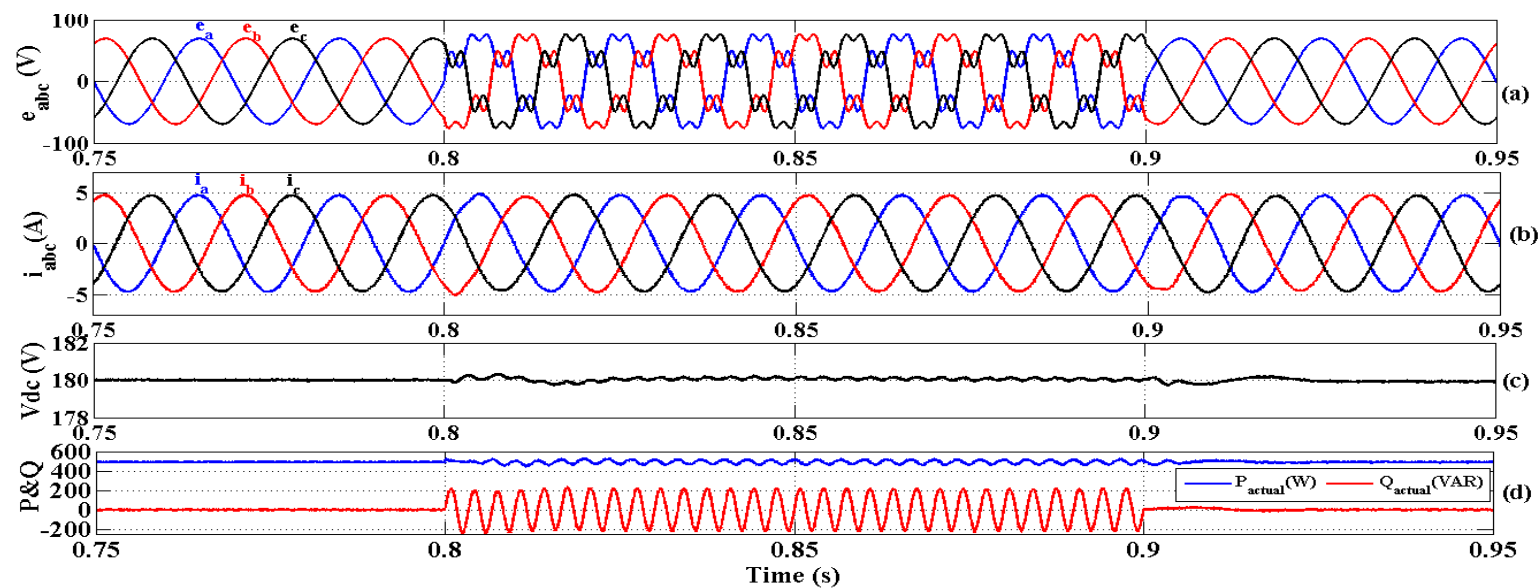

Figure 13. Results for the proposed VF_PDPC of PWM rectifier underbalanced and distorted Input voltages with 7th and 5th harmonic (a) grid voltage (b) grid current (c) DC voltage (d) actual active and reactive power.

Figure 13 (a), represents the simulation results of the three-phase PWM rectifier when the input voltages are infected by fifth $\left(5^{\text {th }} 20 \%\right)$ and seventh harmonic components with a magnitude of $\left(7^{\text {th }} 25 \%\right)$ of the fundamentals. It is noted from Figure 13 (b) that the proposed VF_PDPC guarantees quasi-sinusoidal input current waveform with THD $=1.34 \%$.

Figure 13 (c) and (d), exhibit that the controlled powers and the DC link voltage are kept very close to their references. The presence of the $5^{\text {th }}$ harmonic creates oscillating content at a frequency of $(6 \mathrm{w})$ in the active power and the capacitance-voltage, on the other hand, the $7^{\text {th }}$ harmonic creates an oscillating content at the frequency $(-6 \mathrm{w})$. This finding explains the disappearance of oscillations in active power and DC voltage under disturbed grid voltage infected by the $5^{\text {th }}$ and $7^{\text {th }}$ harmonics. 
This proposed VF_PDPC assures consumption of sinusoidal and balanced line currents at the input of PWM converter, elimination of low order harmonic currents and unity power factor operation under different supply voltage conditions.

\section{CONCLUSION}

This paper presents the mathematical analysis and numerical implementation of a predictive direct power control based on the new virtual flux method (VF_PDPC) for three-phase PWM rectifiers. The main objectives of the proposed control strategy are, obtaining sinusoidal input currents in different input voltage conditions and maintaining the DC bus voltage at the required level.

The proposed VF_PDPC is based on the principle of disturbance rejection. The voltage sensorless control process involves the estimation of the VF components using the pure integrator and the elimination of the DC offset through a simple algorithm, which calculates the average value and subtract it from the instantaneous value of flux. Subsequently, the estimated VF components are used as inputs for the sensorless VF-PDPC controller. The instantaneous active and reactive powers provided by the harmonic component of the input currents are directly controlled using space vector modulation (SVM). The results of the numerical simulation proved the excellent performance of the proposed (VF_PDPC) scheme, during steady and transient states. Waveforms of input currents are maintained sinusoidal under either unbalanced or distorted input voltage conditions.

\section{REFERENCES}

[1] A. Bechouche et al., "Adaptive AC filter parameter identification for voltage-oriented control of three-phase voltage-source rectifiers," Int. J. Modell. Identification Control, vol. 24, no. 4, pp. 319-331, 2015

[2] A. Bouafia et al., "Predictive direct power control of three-phase pulse-width modulation (PWM) rectifier using space-vector modulation (SVM)," IEEE Trans. Power Electron., vol. 25, no. 1, pp. 228-236, 2010.

[3] J. G. Norniella et al., "Improving the dynamics of virtual-flux-based control of three-phase active rectifiers," IEEE Trans. Ind. Electron., vol. 61, no. 1, pp. 177-187, 2014.

[4] Y. Tao et al., "Voltage sensorless predictive direct power control of three-phase PWM converters," IET Power Electron., vol. 9, no. 5, pp. 1009-1018, 2016

[5] L. Xiao et al., "DC-bus voltage control of grid-connected voltage source converter by using space vector modulated direct power control under unbalanced network conditions," IET Power Electron., vol. 6, no. 5, pp.925-934, 2013

[6] Suul, J.A., Luna, A., Rodriguez, P., and Undeland, Voltage-sensor-less synchronization to unbalanced grids by frequency-adaptive virtual flux estimation. IEEE Transactions on Industrial Electronics, 59(9), 2910- 2923,2012

[7] Ketzer, M.B., and Jacobina, Virtual flux sensorless control for shunt active power filters with quasi-resonant compensators. IEEE Transactions on Power Electronics, 31(7), 4818-4830, 2016

[8] Cho, Y., and Lee,.Virtualflux-based predictive direct power control of three-phase PWM rectifiers with fast dynamic response. IEEE Transactions on Power Electronics, 31(4), 3348-3359, 2016

[9] Ali Bechouche, Djaffar Ould Abdeslam. Sensorless Virtual-Flux Based Predictive Direct Power Control of ThreePhase PWM Rectifiers.IEEE Transactions 978-1-5386-1127--2/17, 2017

[10] A. Bouafia, J.P. Gaubert, A. Chaoui. Direct Power Control Scheme Based on Disturbance Rejection Principle for Three-Phase PWM AC/DC Converter under Different Input Voltage Conditions.J. Electrical Systems 8-4 (2012): 367-383, 2012

[11] Malinowski, M., Kazmierkowski, M.P., and Trzynadlowski, A.M. A comparative study of control techniques for PWM rectifiers in ac adjustable speed drives. IEEE transactions on Power Electronics, 18(6), 13901396.(2003).

[12] Malinowski, M., Kazmierkowski, M.P., Hansen, S., Blaabjerg, F., and Marques, G. D. Virtual flux-based direct power control of three-phase PWM rectifiers. IEEE Transactions on Industry Applications, 37(4),10191027(2001).

[13] Cho, Y., and Lee, K.B. Virtual-flux-based predictive direct power control of three-phase PWM rectifiers with a fast dynamic response. IEEE Transactions on PowerElectronics, 31(4), 3348-3359(2016).

[14] J. Eloy-Garcia, S. Arnaltes, and J. L. Rodriguez-Amenedo, "Direct power control of voltage source inverters with unbalanced grid voltages," in IET Power Electronics, vol. 1, no. 3, pp. 395-407, September 2008.

[15] J. A. Suul, A. Luna, P. Rodríguez and T. Undeland, "Virtual-Flux-Based Voltage-Sensor-Less Power Control for Unbalanced Grid Conditions," in IEEE Transactions on Power Electronics, vol. 27, no. 9, pp. 4071- 4087, Sept. 2012

[16] YuKun Tao, Qinghua Wu, Lei Wang, Wenhu Tang."Voltage sensorless predictive direct power control of threephase PWM converters," IET Power Electronics., pp. 1-10 The Institution of Engineering and Technology 2016.

[17] Yukun Tao* and Wenhu Tang"Virtual Flux and Positive-Sequence Power Based Control of Grid Interfaced Converters Against Unbalanced and Distorted Grid Conditions" J ElectrEng Technol.2018; 13(?): 1921-718

[18] Yongsoo Cho and Kyo-Beum Lee, "Virtual-Flux-Based Predictive Direct Power Control of Three-Phase PWM Rectifiers with Fast Dynamic Response", IEEE Transactions on Power Electronics DOI 10.1109/TPEL.2015.2453129 
[19] M. B. Ketzer and C. B. Jacobina, "Virtual flux sensorless control for shunt active power filters with quasi-resonant compensators," IEEE Trans. Power Electron., vol. 31, no. 7, pp. 4818-4830, July 2016

[20] K. H. Ahmed, A. M. Massoud, S. J. Finney, and B. W. Williams, "Sensorless current control of three-phase inverter-based distributed generation,” IEEE Trans. Power Del., vol. 24, no. 2, pp. 919-929, Apr. 2009.

[21] Z. Zhang, H. Xu, M. Xue, Z. Chen, T. Sun, R. Kennel, and C. M. Hackl, "Predictive control with novel virtual-flux estimation for back-to-back power converters," IEEE Trans. Ind. Electron., vol. 62, no. 5, pp. 2823-2834, May 2015

[22] A. M. Razali, M. A. Rahman, G. George, and N. A. Rahim, "Analysis and design of new switching lookup table for virtual flux direct power control of grid-connected three-phase PWM AC - DC converter,” IEEE Trans. Ind. Appl., vol. 51, no. 2, pp. 1189-1200, March 2015

[23] J. A. Suul, A. Luna, P. Rodr'1guez, and T. Undeland, "Voltage-sensor-less synchronization to unbalanced grids by frequency-adaptive virtual flux estimation," IEEE Trans. Ind. Electron., vol. 59, no. 7, pp. 2910-2923, July 2012.

[24] Suul, J.A.Control of Grid Integrated Voltage Source Converters under Unbalanced Conditions - Development of an Online Frequency Adaptive Virtual Flux Based Approach. Ph.D. Thesis, Norwegian University of Science and Technology, Trondheim, Norway, 2012

[25] J. Hu and B. Wu, "New integration algorithms for estimating motor flux over a wide speed range," IEEE Trans. Power Electron., vol. 13, no. 5, pp. 969-977, Sep. 1998

[26] Marcos B Ketzer, Cursino B. Jacobina," Virtual Flux Sensorless Control for Shunt Active Power Filters with Quasi-Resonant Compensators," IEEE Transactions on Power Electronics, vol.31, no.7,pp.4814-4830, July 2016.

[27] J. González Norniella, José M. Cano, G. Alonso Orcajo, Carlos H. Rojas, J. Francisco Pedrayes, Manés F. Cabanas," Improving the Dynamics of Virtual-Flux-Based Control of Three-Phase Active Rectifiers," IEEE Transactions On Industrial Electronics, Vol. 61, No. 1, January 2014.

[28] Nan Jin, Leilei Guo, Chun Gan, Shiyang Hu, Zhifeng Dou, "Finite-state model predictive power control of threephase bidirectional AC/DC converter under unbalanced grid faults with current harmonic reduction and power compensation”, IET Power Electronics, 2018, Vol. 11 Iss. 2, pp. 348-356, DOI: 10.1049/iet-pel.2017.0209

[29] Ali Bechouche, Hamid Seddiki, Djaffar Ould Abdeslam, Adel Rahoui, Yacine Triki," Predictive Direct Power Control With Virtual-Flux Estimation of Three-Phase PWM Rectifiers Under Nonideal Grid Voltages", 2018 IEEE International Conference on Industrial Technology (ICIT), 20-22 Feb. 2018, Lyon, France 